\title{
Validation of S-NPP VIIRS Day-Night band and M bands performance using ground reference targets of Libya 4 and Dome $C$
}

\author{
Xuexia Chen* ${ }^{1}$, Aisheng $\mathrm{Wu}^{1}$, Xiaoxiong Xiong ${ }^{2}$, Ning Lei ${ }^{1}$, Zhipeng Wang ${ }^{1}$, and Kwofu Chiang ${ }^{1}$ \\ ${ }^{1}$ Science Systems and Applications Incorporation, Lanham, Maryland, 20706 \\ 2 NASA Goddard Space Flight Center, Greenbelt, MD, 20661
}

\begin{abstract}
This paper provides methodologies developed and implemented by the NASA VIIRS Calibration Support Team (VCST) to validate the S-NPP VIIRS Day-Night band (DNB) and M bands calibration performance. The Sensor Data Records produced by the Interface Data Processing Segment (IDPS) and NASA Land Product Evaluation and Algorithm Testing Element (PEATE) are acquired nearly nadir overpass for Libya 4 desert and Dome $\mathrm{C}$ snow surfaces. In the past 3.5 years, the modulated relative spectral responses (RSR) change with time and lead to 3.8\% increase on the DNB sensed solar irradiance and $0.1 \%$ or less increases on the M4-M7 bands. After excluding data before April 5th, 2013, IDPS DNB radiance and reflectance data are consistent with Land PEATE data with $0.6 \%$ or less difference for Libya 4 site and $2 \%$ or less difference for Dome $\mathrm{C}$ site. These difference are caused by inconsistent LUTs and algorithms used in calibration. In Libya 4 site, the SCIAMACHY spectral and modulated RSR derived top of atmosphere (TOA) reflectance are compared with Land PEATE TOA reflectance and they indicate a decrease of $1.2 \%$ and $1.3 \%$, respectively. The radiance of Land PEATE DNB are compared with the simulated radiance from aggregated M bands (M4, M5, and M7). These data trends match well with $2 \%$ or less difference for Libya 4 site and $4 \%$ or less difference for Dome C. This study demonstrate the consistent quality of DNB and M bands calibration for Land PEATE products during operational period and for IDPS products after April $5^{\text {th }}, 2013$.
\end{abstract}

Keywords: VIIRS, Day-Night Band, M bands, calibration, radiance, reflectance, Libya 4, Dome C

\section{INTRODUCTION}

\subsection{NPP VIIRS}

The Suomi National Polar-orbiting Partnership (S-NPP), launched successfully on October 28, 2011, makes a bridge to provide the continuity between NASA's Earth Observing System (EOS) Satellites and the future Joint Polar Satellite System satellites to remotely sense Earth elements, including the land, ocean, and atmosphere $[1,2]$. The Visible Infrared Imaging Radiometer Suite (VIIRS) is a key sensor among the five onboard S-NPP instruments (VIIRS, Cross-Track Infrared Sounder, Ozone Mapping and Profiling Suite, Advanced Technology Microwave Sounder, and Cloud and Earth Radiance Energy System). VIIRS is a cross-track scanning radiometer which collects 22 spectral bands at visible and infrared radiometric measurements of Earth's surface [2]. Among the 22 spectral bands, 5 are imaging resolution bands (Ibands) with $375 \mathrm{~m}$ nadir resolution, 16 are moderate resolution radiometric bands (M-bands) with $750 \mathrm{~m}$ nadir resolution, and one is a panchromatic Day-Night Band (DNB) with $750 \mathrm{~m}$ nadir resolution. The VIIRS Earth view observation scan angles range is $\pm 56.28^{\circ}$ off nadir that generates a swath of about $3000 \mathrm{~km}$ at an observation altitude of $828 \mathrm{~km}$. The VIIRS instrument was powered on November 08, 2011 and the instrument nadir door was opened on November 21, 2011.

The DNB on VIIRS is a visible/near-infrared panchromatic band which can observe the Earth during both daytime and nighttime. The DNB calibration methodology used by the NASA VIIRS Characterization Support Team (VCST) is described in a research by Dr. Lee et al. [4] [5].

\subsection{Reference standard sites}

Radiometrically stable surface targets are widely used as reference to monitor satellite data long term trends [6] [7] . Libya 4 and Dome $\mathrm{C}$ are two among the test sites that are endorsed by the Committee on Earth Observation Satellites (CEOS)

*xuexia.chen@ssaihq.com; phone 1301 867-2047 
Working Group on Calibration and Validation (WGCV) as being "reference standards" (http://calval.cr.usgs.gov/sites_catalog_ceos_sites.php). The Libya 4 desert site [Lat $28.55^{\circ}$, Long $23.39^{\circ}$ ] is close to horizontally uniform and is a relatively homogeneous area covered by sands in Africa. The Libya 4 site are often selected as calibration study site based on its high spatial uniformity and temporally invariant surface cover properties for stable reflectance and bidirectional reflectance distribution function (BRDF) [5] [6] [7]. This site is located in arid regions so as to have low probability of cloudy weather and precipitation.

The Dome $\mathrm{C}$ snow site [Lat $-74.50^{\circ}$, Long $123.00^{\circ}$ ] is a relatively homogeneous surface located on the east Antarctic covered by snow and it has extremely small surface slope. The altitude of the site is $3200 \mathrm{~m}$. Its uniformity properties produce temporally invariant reflectance and BRDF spectral response [8] [9]. It has clear atmosphere with minimized influence of aerosol and atmospheric water vapor comparing with other reference sites [9]. In this cold polar area, there is half year at night time and the summer period, about 4 months, is the best observation time.

\subsection{RSR}

Although the relative spectral response (RSR) of all VIIRS bands were well measured and provided by Government Team in the pre-launch test program [10], the on-orbit radiometric response can change with time due to Rotating Telescope Assembly (RTA) mirror degradation [1] [11]. Shortly after launch, it is observed that several VIIRS bands has decreased optical throughput due to the mirror coating contamination of the RTA [12]. The RTA degradation has been modeled and time dependent modulated RSR are generated and updated to address the degradation impact at radiometric calibration [4] [11]. Table 1 indicated the characteristics of DNB and M4-M7 characteristics and figure 1 shows their modulated RSRs changes. The near infrared bands has been more affected than those in the visible. DNB RSR has changed significantly with time and its peak of the RSR is moving to the short wavelength side from orbit 154 (Nov 08, 2011) to orbit 15000 (Sept 19 $\left.9^{\text {th }}, 2014\right)$.

The VIIRS product quality is based on the radiometric calibration integrity of VIIRS Sensor Data Records (SDR). The main objective in this research is using the ground targets, Libya 4 and Dome C, to monitor the VIIRS RSB calibration stability and performance over the past 3.5 years.

Table 1. List of characteristics of DNB and M bands within DNB wavelength range.

\begin{tabular}{|c|c|c|c|c|c|}
\hline $\begin{array}{c}\text { VIIRS } \\
\text { Band }\end{array}$ & $\begin{array}{c}\text { Central } \\
\text { wavelength }(\boldsymbol{\mu m})\end{array}$ & $\begin{array}{c}\text { Band } \\
\text { width }(\boldsymbol{\mu m})\end{array}$ & $\begin{array}{c}\text { Wavelength } \\
\text { Range }(\boldsymbol{\mu m})\end{array}$ & $\begin{array}{c}\text { Band } \\
\text { Explanation }\end{array}$ & $\begin{array}{c}\text { Spatial Resolution } \\
\text { at nadir }(\mathbf{m})\end{array}$ \\
\hline DNB & 0.7 & 0.4 & $0.5-0.9$ & Visible/Reflective & 750 across full scan \\
\hline M4 & 0.555 & 0.02 & $0.545-0.565$ & \multirow{2}{*}{ Visible/reflective } & 750 \\
\cline { 1 - 4 } M5 & 0.672 & 0.02 & $0.662-0.682$ & & 750 \\
\hline M6 & 0.746 & 0.015 & $0.739-0.754$ & \multirow{2}{*}{ Near IR } & 750 \\
\cline { 1 - 3 } \cline { 1 - 1 } M7 & 0.865 & 0.039 & $0.846-0.885$ & & 750 \\
\hline
\end{tabular}

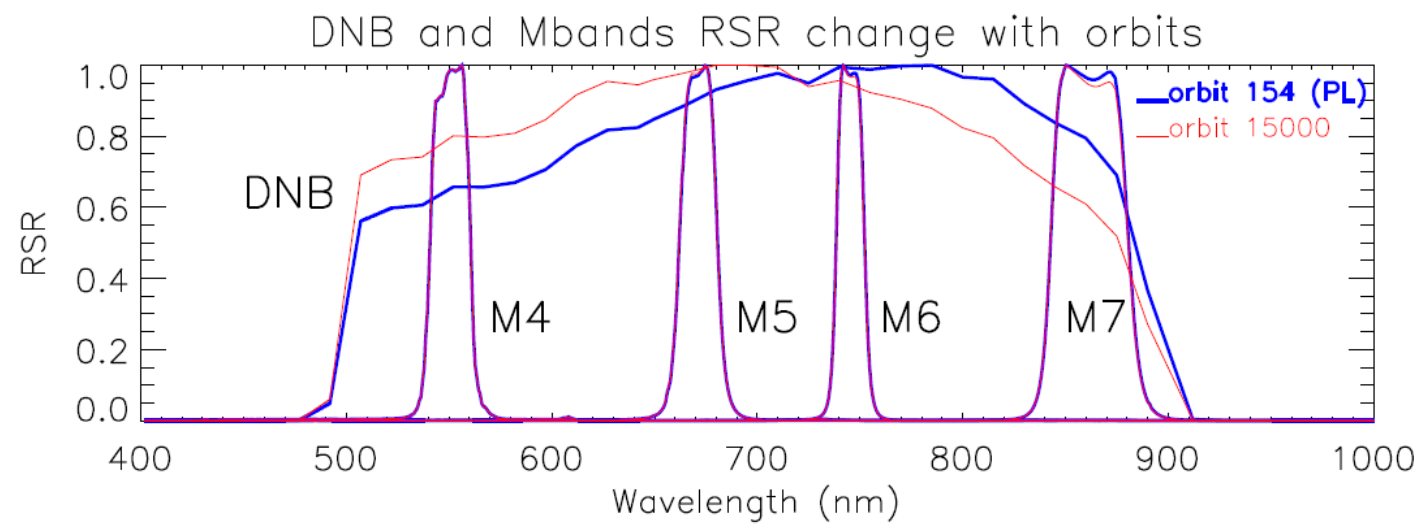

Figure 1. DNB and M bands prelaunch RSR at orbit 154 and modulated RSR at orbit 15000. 


\section{DATA AND METHOD}

\subsection{Data}

In this study, the solar irradiance LUT and the modulated RSR LUTs are provided by the VCST. The DNB and M bands SDR produced by the Interface Data Processing Segment (IDPS) and NASA Land Product Evaluation and Algorithm Testing Element (PEATE) are downloaded from Level 1 and Atmosphere Archive and Distribution System (LAADS) (http://ladsweb.nascom.nasa.gov/). We selected both data nearly nadir overpass for Libya 4 and Dome C since VIIRS launched to the most recent available data in June 2015. The IDPS data is the NOAA-CLASS archived NPP-VIIRS data, based on the NOAA official calibration which calibration LUTs are updated only over time and no reprocessing over the record. Land PEATE data is based on research processing and are calibrated using LUTs provided by VCST team which is led by Dr. Xiaoxiong Xiong [1]. The Land PEATE data has been reprocessed when calibration algorithms is improved.

Images without visible clouds or shadow over Libya 4 and Dome $\mathrm{C}$ sites are selected beside the study site center pixel has less than 100 pixel distances to the nadir view (about $75 \mathrm{~km}$ ). We extracted 32 by 32 pixels area to calculate the DNB mean radiance and reflectance and use $M$ band pixels at the same geolocation to calculate the $M$ bands mean radiance and reflectance. More detail of calculation algorithm is provided below for different sites. We exclude the images with standard deviation of radiance higher than 0.0001. In Dome C, we also exclude the data with solar zenith angle higher than 80 degree. Based on the above requirements, Libya 4 site images are selected from 16-day repeatable orbits so each data has the similar viewing geometry relative to the site. Selected Dome $\mathrm{C}$ site images have more overpass orbits with different viewing geometry parameters.

\subsection{Libya 4 radiance and reflectance calculation}

In our downloaded data, the SDRs of DNB include calibrated and geolocated radiance data and the M bands SDRs contain calibrated and geolocated radiance and reflectance data. To investigate the Earth-Sun distance and solar zenith angle normalized radiance, we used equation (1)

$$
\begin{aligned}
\qquad L_{\text {normalized }}=\frac{L_{m} * d^{2}}{\cos (\theta)} & \text { (1) } \\
L_{\text {normalized }} & =\text { Measured solar radiance after Earth-Sun distance and solar zenith angle normalization }\left(\mathrm{W} \cdot \mathrm{cm}^{-2} \cdot \mathrm{Sr}^{-1}\right) \\
L_{m} & =\text { Measured solar radiance provided by the SDR DNB product }\left(\mathrm{W} \cdot \mathrm{cm}^{-2} \cdot \mathrm{Sr}^{-1}\right) \\
d & =\text { Earth-Sun distance (astronomical units) } \\
\theta= & \text { Solar zenith angle }
\end{aligned}
$$

To retrieve the Libya 4 DNB Earth-Sun distance normalized TOA reflectance data, we use the equation (2).

$$
\rho_{T O A}=\frac{\pi^{*} L_{m} * d^{2}}{\cos (\theta) * E S U N_{\lambda}}
$$

\footnotetext{
$\rho_{T O A}=$ Top of atmosphere reflectance with Earth-Sun distance normalization

$\operatorname{ESUN}_{\lambda}=$ Band dependent mean solar irradiance $\left(\mathrm{W} \cdot \mathrm{m}^{-2} \cdot \mathrm{nm}^{-1}\right)$.
}

$L_{m}$ is provided by the SDRs product which is calibrated considering the relative response versus scan angle of the HAM and the SD BRDF degradation using the time dependent modulated RSR [1] [11]. $E S U N_{\lambda}$ is referred to as the band pass and is calculated using equation (3).

$$
\operatorname{ESUN}_{\lambda}=\frac{\sum\left(R S R_{\lambda} * \text { SolarIrradiance }_{\lambda} * \Delta \lambda\right)}{\sum\left(R S R_{\lambda} * \Delta \lambda\right)}
$$

SolarIrradiance $_{\lambda}=$ Solar spectral irradiance from VCST LUT $\left(\mathrm{W} \cdot \mathrm{m}^{-2} \cdot \mathrm{nm}^{-1}\right)$

\footnotetext{
*xuexia.chen@ssaihq.com; phone 1301 867-2047
} 
$R S R_{\lambda}=$ Wavelength dependent relative spectral response of band $\lambda$

$\Delta \lambda=$ Wavelength spectral interval $(\mathrm{nm})$

$\mathrm{M}$ bands radiance $\left(L_{m_{-} M b a n d}\right)$ and reflectance $\left(\rho_{\text {TOA_Mband }}\right)$ data are calculated by using the scaled integer (SI), scale, and offset values provided by the SDR products following equations (4) - (6).

$$
\begin{gathered}
L_{m_{-} \text {Mband }}=S I * \text { scale }+ \text { offset } \\
L_{\text {normalized_Mband }}=\frac{L_{m_{-} \text {Mband }} * d^{2}}{\cos (\theta)} \\
\rho_{\text {TOA_Mband }}=S I * \text { scale }+ \text { offset }
\end{gathered}
$$

In this study, we also use the Libya 4 SCIAMACHY spectral data to retrieve the modulated TOA reflectance. SCIAMACHY spectral data acquired over Libya 4 site from 2002 to 2010 are processed to derive the average TOA reflectance spectra. The SCIAMACHY data footprint is $30 \mathrm{~km}$ x $240 \mathrm{~km}$ and it has a very fine spectral resolution (with < $1 \mathrm{~nm}$ ) [13]. Thus SCIAMACHY can provide a high spectral precision of the Libya 4 site by sampling several absorption features (Figure 2). In this study, we use the equation (7) to calculate the modulated TOA reflectance considering the RSR influence with time.

$$
\rho_{\text {TOA }_{-} \text {model }}=\frac{\sum\left(\rho_{\text {SCIAMACHY }} * \text { SolarIrradiance }_{\lambda} * R S R_{\lambda} * \Delta \lambda\right)}{\sum\left(R S R_{\lambda} * \text { SolarIrradiance }_{\lambda} * \Delta \lambda\right)}
$$

$\rho_{\text {SCIAMACHY }}$ is the SCIAMACHY spectral indicated in figure 2 . The $\rho_{\text {TOA }} \bmod e l$ is calculated based on the assumption that the surface spectral and solar irradiance did not change, and the time dependent RSR is the only source for the reflectance change.

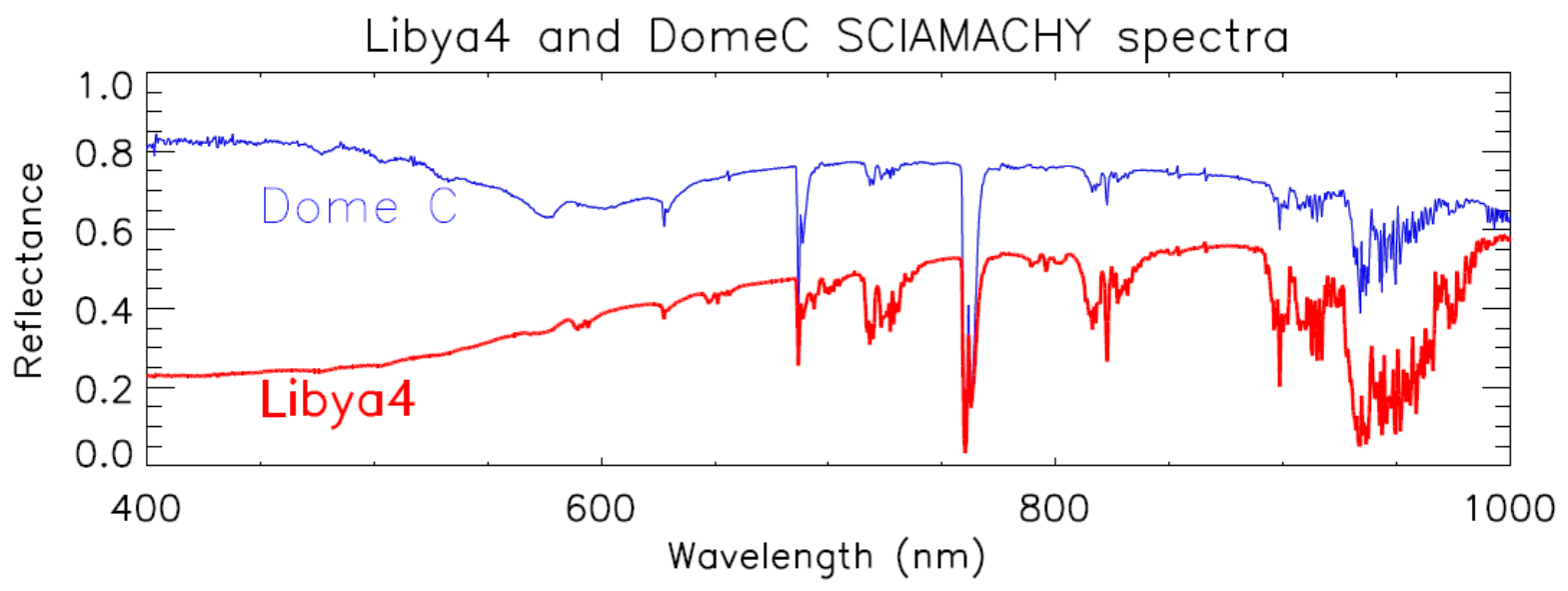

Figure 2. SCIAMACHY spectra of Libya 4 and Dome C.

In this study, we compared DNB with the M bands within the DNB wavelength range except M6 which is lack of high quality data due to saturation. An integrated DNB radiance using M4, M5, and M7 Bands are compared with DNB for long term trend monitoring following the equations (8), (9), (10) and (11).

$$
\begin{gathered}
R_{m i}=\frac{\int R S R(\text { Mband })_{\lambda} * R S R(D N B)_{\lambda^{*}} \rho_{\lambda^{*}} d_{\lambda}}{\int R S R(D N B)_{\lambda^{*}} \rho_{\lambda *} * d_{\lambda}} \\
W_{m i}=\frac{R_{m i}}{R_{m 4}+R_{m 5}+R_{m 7}}
\end{gathered}
$$




$$
\begin{gathered}
D N B_{\text {bandwide }}=\int R S R(D N B)_{\lambda} * d_{\lambda} \\
\text { Integral }_{\text {Mbands }}=\left(W_{m 4} * L_{m 4}+W_{m 5} * L_{m 5}+W_{m 7} * L_{m 7}\right) * D N B_{\text {bandwide }}
\end{gathered}
$$

$\boldsymbol{R}_{\boldsymbol{m} i}$ are weight parameters of M bands 4, 5, and 7 to compare with DNB. $\boldsymbol{W}_{\boldsymbol{m} \boldsymbol{i}}$ are the adjusted weights that contained the scale for making all weights' sum as 1 . The integral $\mathrm{M}$ bands radiance, Integral $\boldsymbol{M b a n d s}_{\text {, }}$, are calculated in equation 11 using the $\boldsymbol{L}_{\boldsymbol{m} i}$, which are the M bands radiance normalized by solar zenith angle and Earth-Sun distance, and the DNB RSR band wide parameter, $\boldsymbol{D N} \boldsymbol{B}_{\text {bandwide, }}$ which is calculated in equation (10).

\subsection{Dome $\mathrm{C}$ radiance and reflectance calculation}

The methodology used to characterize the long term trend of Dome C site is similar as the Libya 4 site except the BRDF influence. In Dome C site, the BRDF of the snow is nearly constant for the spectrum from 500 to $900 \mathrm{~nm}$ for a specific solar zenith angle, but the reflected radiance in different angular distribution is more isotropic because of atmospheric Rayleigh scattering [8]. The smooth snow surface causes very little effect of varying azimuth angle between the sun and the surface roughness features' dominant orientation direction [8]. From our data, we found that cosine solar zenith angle can't well correct the BRDF influence in Dome C, thus we use a linear fit between solar zenith angle and the radiance normalized by Earth-Sun distance and RSR factor using the first year period of data [5]. This linear BRDF correction can remove mostly the solar zenith angle and atmospheric Rayleigh scattering influence due to different season and atmosphere status in Dome C site.

$L_{\text {normalized_dis_rsr }}$ is the radiance normalized with Earth-Sun distance and RSR correction $\left(\mathrm{W} \cdot \mathrm{cm}^{-2} \cdot \mathrm{Sr}^{-1}\right)$ and is calculated based on the equations (12) and (13). $F_{E S U N}$ is the ratio of ESUN between the data collection time $t$ and the reference time t0 (prelaunch, orbit 154).

$$
\begin{aligned}
& L_{\text {normalized_dis_r } r s r}=\frac{L_{m} * d^{2}}{F_{E S U N}} \\
& F_{E S U N}=\frac{E S U N_{t}}{E S U N_{t 0}}
\end{aligned}
$$

Once we have all $L_{\text {normalized_dis_rsr }}$ and solar zenith angle $\theta$ data from different collection time, we use the first year's good quality data to derive linear regression coefficients $f_{0}$ and $f_{l}$ in equation (14). The ratio factor, $F_{b r d f}$, for Dome $\mathrm{C}$ site is calculated in equation 15 as a time dependent parameter where $\theta_{0}$ is the reference angle (60 degree), $\theta_{t}$ is the solar zenith angle at data collection time.

$$
\begin{aligned}
& L_{\text {normalized_dis_rsr }}=f_{0}+f_{1} * \theta \\
& F_{\text {brdf }}=\frac{f_{0}+f_{1} * \theta_{t}}{f_{0}+f_{1} * \theta_{0}}
\end{aligned}
$$

$L_{\text {normalized_dis_brdf }}$ is the radiance with Earth-Sun distance and BRDF normalization and is calculated with equation (16).

This normalized radiance is used for our long term trend monitoring and the integral study using $\mathrm{M}$ bands. The TOA reflectance of Dome C is calculated in equation (17) which considers the BRDF correction and RSR correction.

$$
L_{\text {normalized_dis_brdf }}=\frac{L_{m} * d^{2} * F_{b r d f}}{\cos \left(\theta_{0}\right)}
$$

\footnotetext{
*xuexia.chen@ssaihq.com; phone 1301 867-2047
} 


$$
\rho_{\text {TOA_DomeC }}=\frac{\pi * L_{m} * d^{2} * F_{b r d f}}{\cos \left(\theta_{0}\right) * E S U N_{\lambda}}
$$

Dome C M bands radiance and reflectance data are calculated by using the SI, scale, and offset provided by the SDR products and also the linear BRDF correction are processed using similar method provided above. In addition, the integrated $\mathrm{M}$ bands radiance are calculated using methods described in section 2.2.

\section{RESULTS}

\subsection{DNB RSR influence on ESUN}

The changes of modulated RSR cause band dependent solar irradiance (ESUN) changes. Figure 3 indicate the quadratic fit of normalized ESUN difference using modulated RSR of DNB and M7. Comparing to orbit 154 (November 8th, 2011), the prelaunch data, there are about 3.8\% increase of ESUN at DNB and about $0.1 \%$ increase in M7 during the past 3.5 years. The ESUN changes at M4, M5, and M6 bands are not significant with about $0.1 \%, 0.095 \%$, and $0.065 \%$ increase.

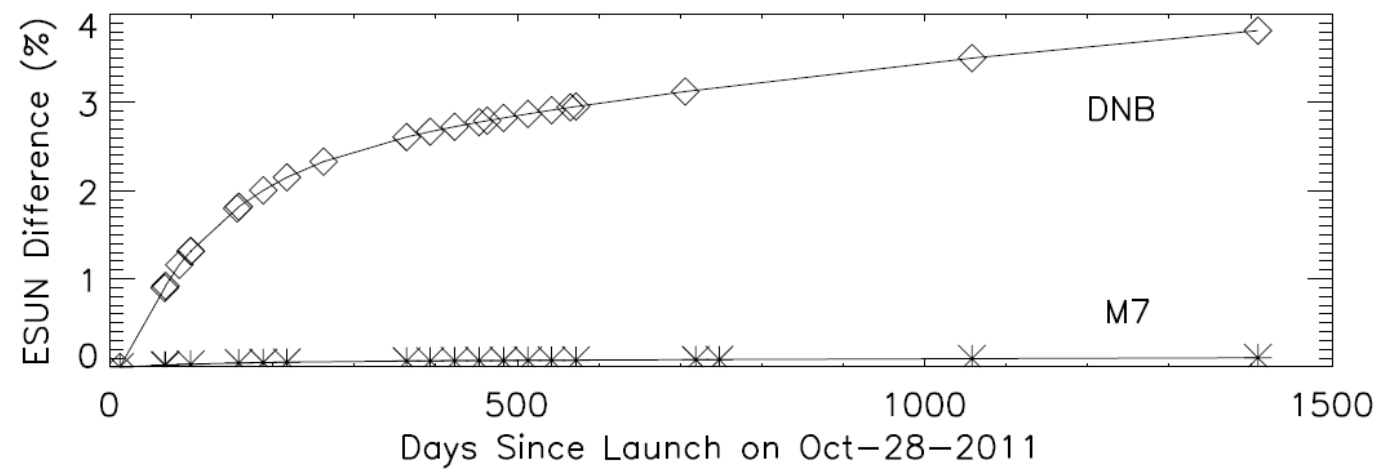

Figure 3. Normalized DNB and M7 ESUN values derived from modulated RSRs.

\subsection{Libya 4 site radiance and reflectance long term trends}

In Libya 4 site, the solar zenith angle normalization and Earth-Sun distance normalization have significantly removed the seasonal variation in the long term data trend. Figure 4 indicate the long term trends of Libya 4 radiance and reflectance. Because the LUT updates, the IDPS long term trends have upward increase trend with time (about $14 \%-16 \%$ increase by 2014 May 31). The Land PEATE data have a more stable long term trend due to better quality of LUTs updates and historical data reprocessing. The reflectance of DNB show similar trends as radiance. The noticeable difference in IDPS and Land PEATE trends are caused by the existing inconsistent calibration through the IDPS data processing mission, including the use of SDSM screen transmission and algorithms, and RSR degradation used to compute and update the RSB gain coefficients. The M bands, including M4, M5, and M7 within the DNB wavelength range, are stable and do not have obvious upward trends.

Land PEATE and SCIAMACHY derived modulated TOA reflectance data are normalized to the first data point and their trends are shown in figure 5. Even we assume the surface SCIAMACHY reflectance spectra and Solar Irradiance LUT do not change, when the DNB modulated RSR change, the SCIAMACHY derived TOA reflectance has a $1.2 \%$ decrease in the past 3.5 years. The Land PEATE data derived TOA reflectance trend has large seasonal oscillation (figure 5). The quadratic fit of first three years Land PEATE data are normalized to the first data point and the trend indicate a $1.3 \%$ decrease in the past 3.5 years. These two trends match well and are consistent that demonstrate the Land PEATE reflectance changes are mostly caused by the RSR change instead of ground target change. 
The ratio of radiance and reflectance between IDPS and Land PEATE data are large before April 5th, 2013 with maximum difference about $9.5 \%$. After IDPS RSR LUT updates, the difference is much less and most data are within $0.6 \%$ difference. This demonstrate that IDPS and Land PEATE data sets are stable and consistent in recent years.

The integral DNB radiance from M4, M5, and M7 bands are compared with measured DNB radiance after Earth-Sun distance and solar zenith angle normalization (Figure 6). Their seasonal variation is very similar and the values are close. The weights for M bands are changed with time due to the RSR change. The ratio between integral M bands radiance to DNB radiance ranges from 0.99 to 1.02
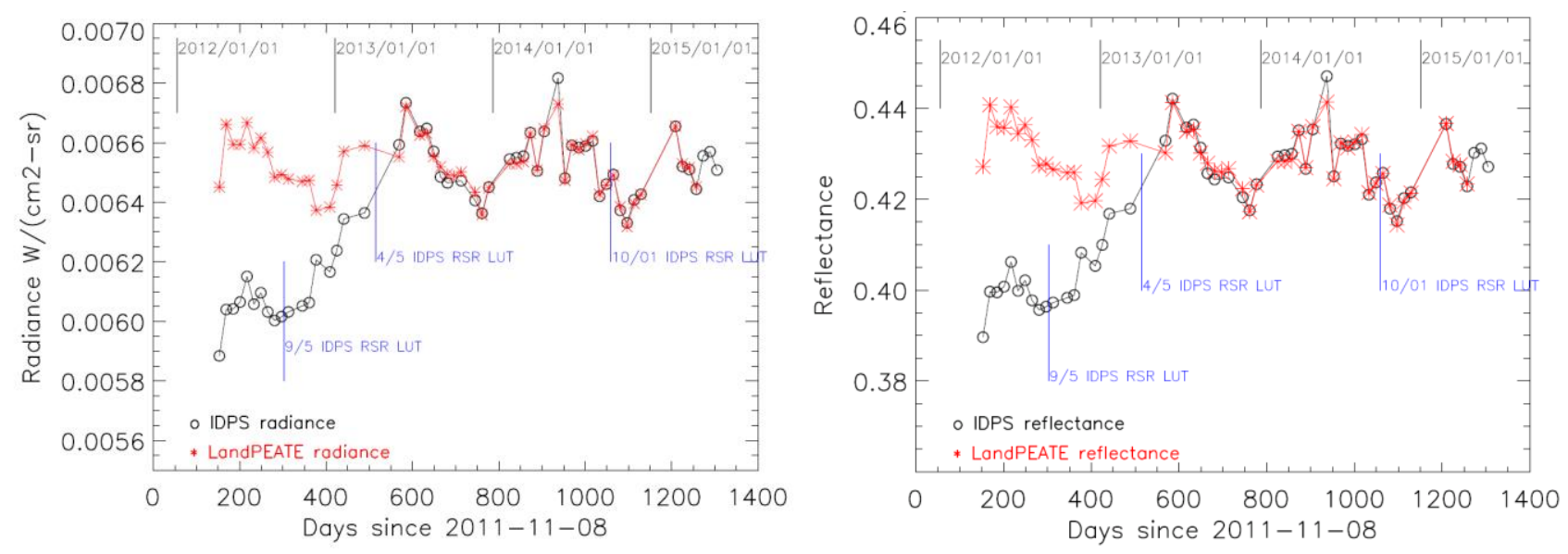

Figure 4. Libya 4 DNB radiance and reflectance of IDPS and Land PEATE data for $32 \times 32$ pixels area.

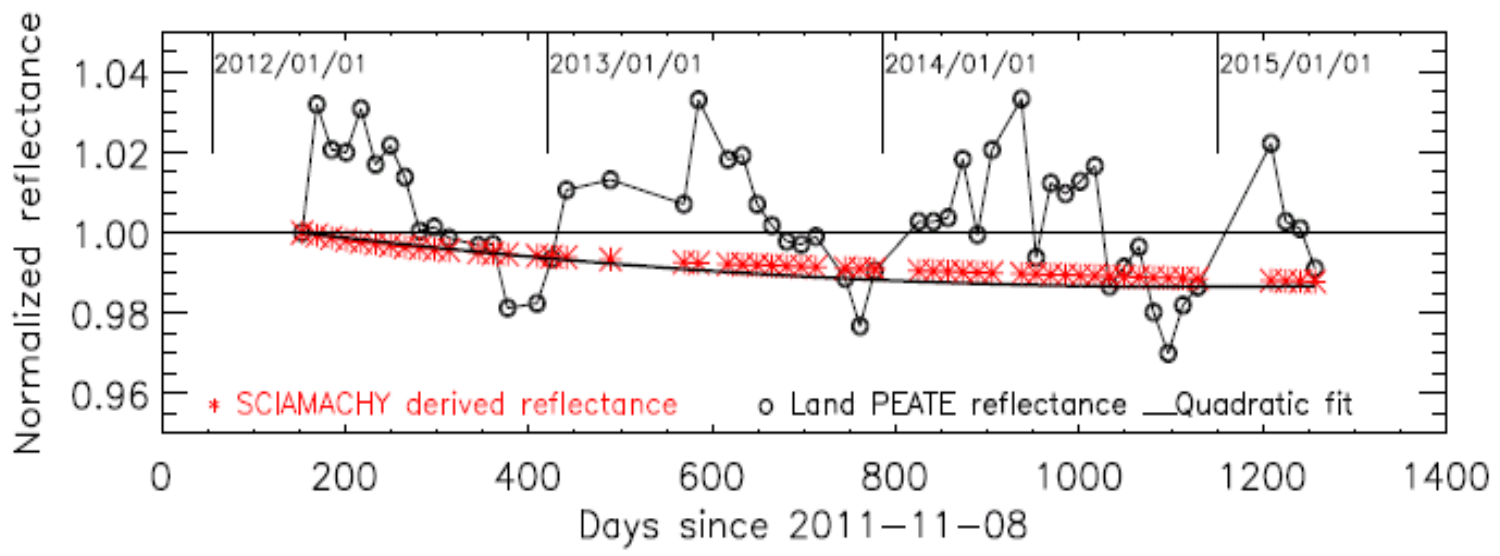

Figure 5. Libya 4 DNB normalized TOA reflectance of Land PEATE and SCHIAMACHY derived data. 


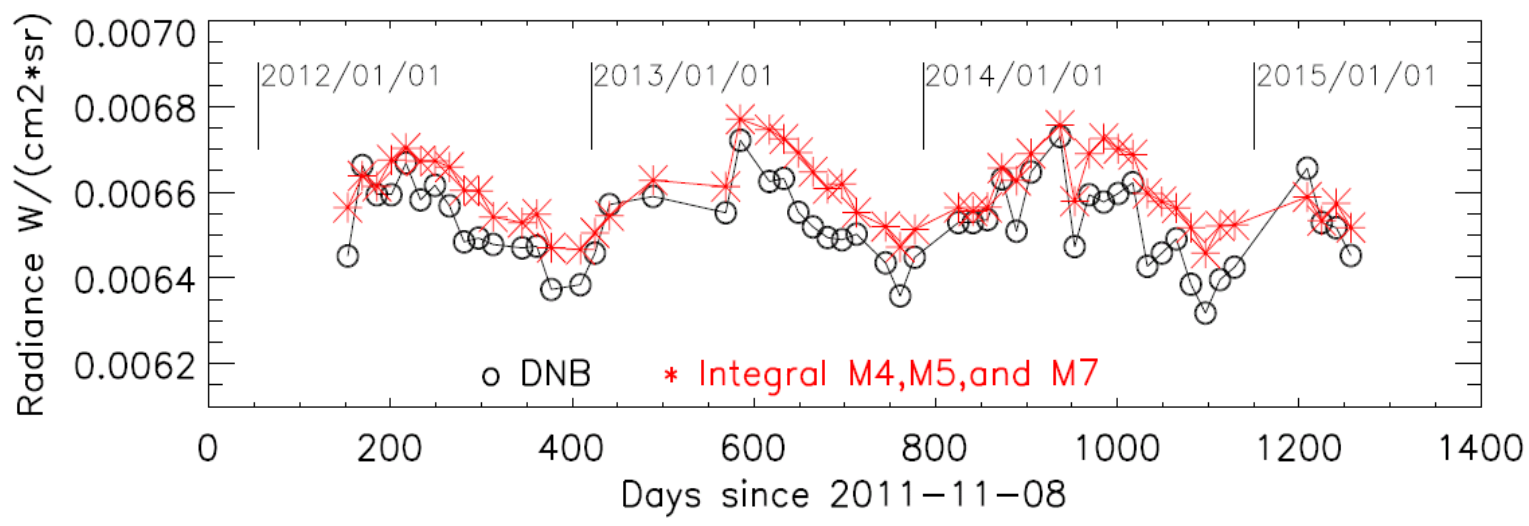

Figure 6. Libya 4 DNB radiance and integral $\mathrm{M}$ bands radiance comparison for $32 \times 32$ pixels overlap area.

\subsection{Dome $\mathrm{C}$ site radiance and reflectance long term trends}

The linear fit for BRDF correction for Dome C site Land PEATE data is indicated in figure 7. We use 2012 data as linear fitting training data to derive ratio $\boldsymbol{F}_{\boldsymbol{b r d f}}$ factor. Each data point represents mean radiance of $32 \times 32$ pixels at site after EarthSun distance normalization and RSR correction. The fitted radiance data with 60 degree solar zenith angle is used as BRDF correction reference. The other data are normalized to this reference data. After BRDF correction, the IDPS and Land PEATE radiance and reflectance data for Dome $\mathrm{C}$ are indicated in figure 8. The IDPS data before 2013 April 5th have significant lower values than Land PEATE data due to the difference of RSR LUTs updates. After that, the ratio of radiance and reflectance between IDPS and Land PEATE data are $2.0 \%$ or less.

The integral radiance from M4, M5, and M7 bands are compared with DNB radiance in figure 9. These radiance data are normalized with Earth-Sun distance and $\boldsymbol{F}_{b r d f}$ at 60 degree solar zenith angle. Their seasonal variation is very similar and the values are close. The weights for $\mathrm{M}$ bands are changed with time due to the RSR change and the ratio between integral $\mathrm{M}$ bands radiance to DNB radiance ranges from 0.96 to 0.98 . The ratio at Dome $\mathrm{C}$ site is slightly different from the Libya 4 site because the surface spectral characteristics are different though the modulated RSR changes are the same.

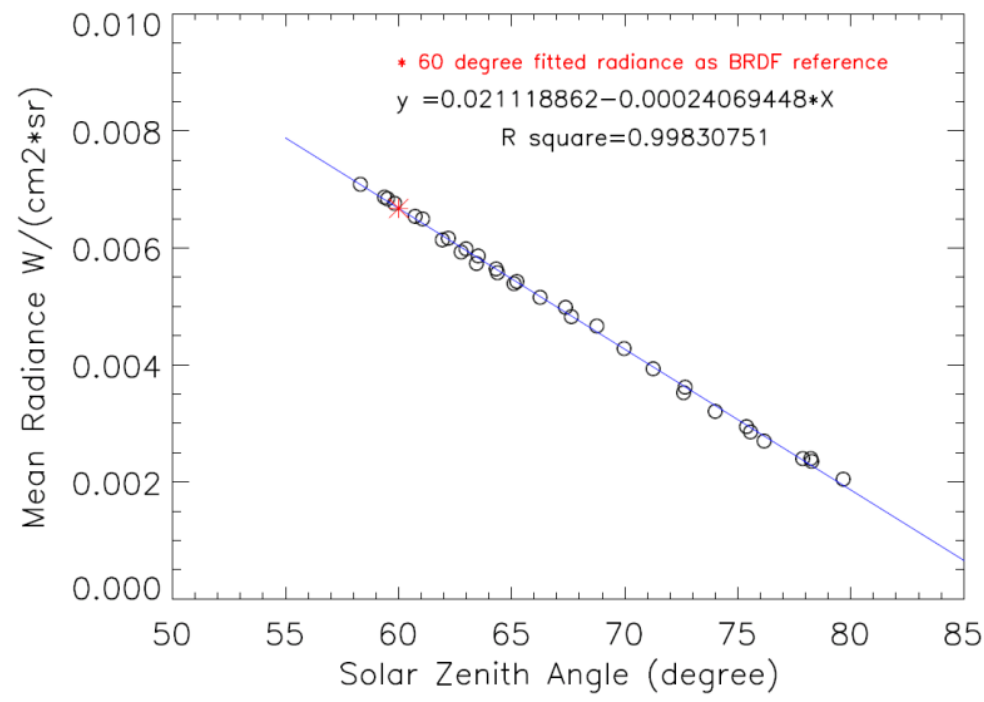

Figure 7. Dome C DNB BRDF linear fit using first year data in 2012. 

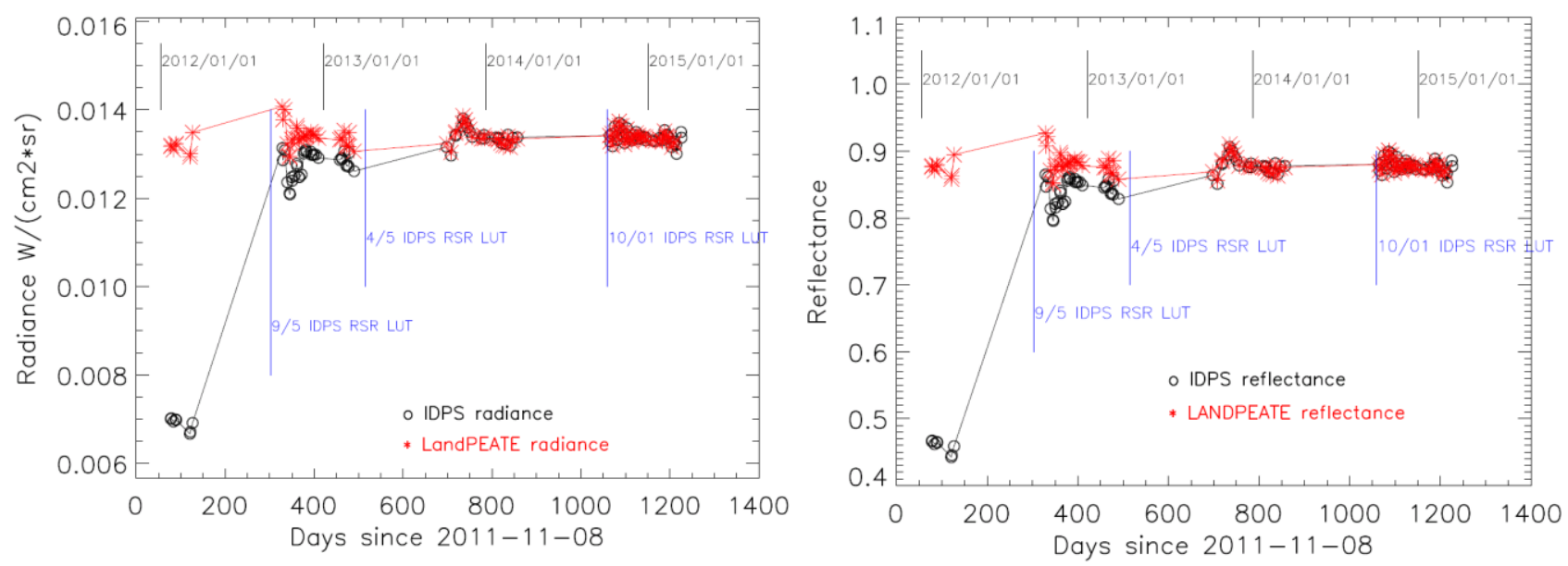

Figure 8. Dome C DNB radiance and reflectance of IDPS and Land PEATE data for 32x32 pixel area.

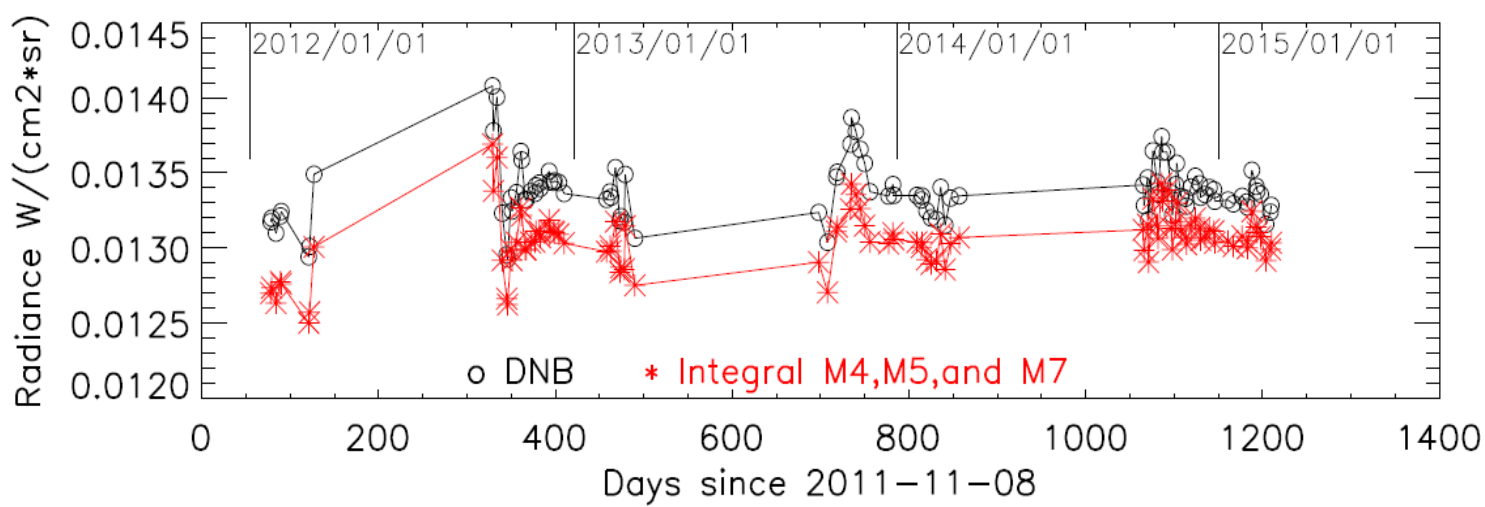

Figure 9. Dome C DNB radiance and integrated M bands radiance of Land PEATE data for 32 x 32 pixels overlap area.

\section{CONCLUSIONS}

The Suomi NPP VIIRS has been operating normally to daily collection of global data for more than three and half years now. In this study, we use two independent sites, Libya 4 and Dome C, to validate VIIRS DNB and M bands calibration performance using nadir overpass images. DNB modulated RSR introduce about 3.8\% increase on band dependent solar irradiance, the M4-M7 bands RSR influence is $0.1 \%, 0.097 \%, 0.065 \%$, and $0.1 \%$, respectively.

Impacts of solar zenith angles on the observed radiance and reflectance are corrected based on cosine solar zenith angle for Libya 4 site and linear fit of solar zenith angle for Dome $\mathrm{C}$ site. After excluding some early mission data points (before April $\left.5^{\text {th }}, 2013\right)$, IDPS to Land PEATE data ratio in both radiance and reflectance are consistent and with $0.6 \%$ or less difference for Libya 4 site and $2.0 \%$ or less difference for Dome $\mathrm{C}$ site. The noticeable trends difference in early data collection period are caused by the inconsistent calibration LUTs during data processing mission, including the use of SDSM screen transmission and algorithms, and RSR degradation and other relative LUTs.

The theoretical TOA reflectance long term trend calculated from SCIAMACHY Libya 4 surface spectra and DNB RSR data indicate a decrease trend about $1.2 \%$ in the past 3.5 years. The quadratic regression of Land PEATE DNB reflectance at Libya 4 site shows a decrease of $1.3 \%$ in long term trend. This demonstrate that the Land PEATE data long term trend change are mostly caused by RSR influence instead of ground target change.

Though we will need longer VIIRS observation time and more time series data to better understand and verify the NPP

*xuexia.chen@ssaihq.com; phone 1301 867-2047 
VIIRS IDPS and Land PEATE data quality, results of this study provide useful information on VIIRS post-launch calibration assessment and preliminary analysis of its calibration stability and consistency for the first 3.5 years. Based on the above results, VIIRS Land PEATE data is suitable for long term monitoring tasks due to its stable radiometric calibration and data reprocessing procedure with improved calibration algorithm. If IDPS data are used for long term monitoring, we suggest using the data after April $5^{\text {th }}, 2013$ which contain better quality LUTs than early mission data. It should be noticed for scientists that the RSR influence at DNB radiance and reflectance need to be considered when using DNB products for long term change detection.

\section{ACKNOWLEDGMENTS}

We thank Shiyan Lee and Samuel Anderson for providing the RSR data. All the SCIAMACHY data is distributed by the European Space Agency. Jon Fulbright and Boryana Efremova also provide comments on our pilot study results.

\section{REFERENCES}

[1] Xiong, X., Butler, J., Chiang, K., Efremova, B., Fulbright, J., Lei, N., McIntire, J., Oudrari, H., Sun, J., Wang, Z., and Wu, A., "VIIRS on-orbit calibration methodology and performance", Journal of Geophysical Research: Atmospheres, vol. 119, pp. 1-11, (2014).

[2] Butler,J., Xiong, X., oudrari, H., Pan, c. , and Gleason, J., "NASA calibration and characterization in the NOESS Preparatory Project (NPP)", IGARSS, (2009).

[3] Lee, S., McIntire, J., Oudrari, H., Schwarting, T., and Xiong, X., "A new method for Suomi-NPP Day-Night Band onorbit radiometric calibration", IEEE Transactions on Geoscience and Remote Sensing, vol. 53, no. 1, pp. 324-334, (2015).

[4] Xiong, X., Lee, S., Wang, Z., Wu, A., Chen, X., Lei, N., and Fulbright, J., "On-orbit calibration and validation methodologies for S-NPP VIIRS Day Night Bands (DNB)," in Earth Obsering Systems XIX, Conference of SPIE, San Diego, (2014).

[5] Wu, A., Xiong, X., Cao, C., and Angal, A., "Monitoring MODIS calibration stability of visible and near-IR bands from observaed top-of-atmosphere BRDF-normalized reflectances over Libyan desert and Antartic surfaces", in Earth Observing systems XIII, Proceedings of SPIE, San Diego, (2008).

[6] Angal, A., Xiong. X., Choi, T., Chander, G., and Wu, A., "Using the Sonoran and Libyan Desert Test Sites to monitor the temporal stability of reflective solar bands for Landsat 7 ETM+ and Terra MODIS sensors", Journal of Applied Remote Sensing, vol. 4, no. 1, pp. 043525-12, (2010).

[7] Hudson, S.r., Wang, S.G., Brandt, R.E., Grenfell, T.C., and Six, D., "Spectral bidirectional reflectance of Antarctic snow: measurements and parameterization", Journal of Geophysical Research, vol. 111, p. D018106, (2006).

[8] Chander, G., "Questionnaire for information regarding the CEOS WGCV IVOS subgroup Cal/Val test sites for land imager radiometric gain", QA4EO-WGCV-IVO-CSP-001, (2009).

[9] Moeller, C., Mcintire, J., Schwarting, T., and Moyer, D., "VIIRS F1 'best' relative spectral response charaterization by the government team", Earth Observing System, XVI, Proceeding of SPIE, San Diego, (2011).

[10] Lei, N., Xiong, X., and Guenther, B., "Modeling the detector radiometric gains of the Suomi NPP VIIRS reflective solar bands", IEEE Transactions on Geoscience and Remote Sensing, vol. 53, no. 3, pp. 1565-1573, (2015).

[11] Barrie, J.D., Fuqua, P.D., Meshishnek, M.J., ciofalo, M.R., Chu, C.T., Chaney, J.A., Moision R.M., and Graziani, L., "Root Cause Determination of On-orbit Degradation of the VIIRS Rotating Telescope Assembly", Proc. of SPIE, Vol. $8510,(2012)$.

[12] Gyanesh, C., Mishra, N., Helder, D.L., Aaron, d.B., angal, A., choi, T., Xiiong, X., and Doelling, D.R., “Applications of spectral band adjustment factors (SBAF) for cross-calibration", IEEE Transactions on Geoscience and Remote Sensing, vol. 51, no. 3, pp. 1267-1281, (2013).

[13] Lee, S., sun, C., Chiang, V., Xiong, X., "An Overview of NASA VCST SNPP VIIRS Day-Night Band On-Orbit Calibration Methodology", Proceedings of SPIE 9218, Earth Observing Systems XIX, San Diego, (2014).

[14] Wu, a., Xiong, X., Cao, X., and Sun, C., "Monitoring NPP VIIRS on-orbit radiometric performance from TOA reflectance time series", Earth Observing Systems XVIII, Proceedings of SPIE, San Diego, (2013). 